\title{
MODELO INTERATIVO NA INCLUSÃO ESCOLAR: UM DESAFIO NA EDUCAÇÃO EM NAMPULA - MOÇAMBIQUE
}

\section{INTERACTIVE MODEL IN SCHOOL INCLUSION: A CHALLENGE IN EDUCATION IN NAMPULA MOZAMBIQUE}

\author{
Rosario Martinho Sunde
}

\begin{abstract}
RESUMO
A inclusão é uma das abordagens mais discutida na atualidade no campo da educação, por exigir adaptações às condições individuais das crianças. $O$ presente artigo, tem com tema; modelo interativo de inclusão escolar, tem como objetivo discutir a promoção da inclusão escolar de crianças portadoras de deficiências a partir de modelos interativos. O mesmo é fruto de experiências socioprofissionais que o autor foi vivenciando durante alguns anos como cidadão e docente de Necessidades Educativas Especiais na Universidade Pedagógica de Moçambique, Delegação de Nampula ${ }^{1}$. O estudo se apoia em experiências profissionais e leituras obras literária que teoricamente discutem o fenômeno de inclusão escolar e apresentam possíveis estratégias de interação professor-aluno, aluno-aluno entre outros intervenientes no processo. O artigo não traz soluções, mas algumas sugestões em forma de modelos de procedimentos dos intervenientes no processo de inclusão escolar de alunos com Necessidades Educativas Especiais em turmas regulares.
\end{abstract}

Palavras-chave: Modelo; Interação; Inclusão escolar; Crianças

\begin{abstract}
Inclusion is one of the most discussed approaches today in the field of education, because it requires adaptations to the individual conditions of children. This article has as its theme; an interactive model for school inclusion, aims to promote the school inclusion of children with disabilities based on interactive models. The same is the result of socio-professional experiences that the author has been experiencing for some years as a citizen and teacher of Special Educational Needs at the Pedagogical University of Mozambique, Delegation of Nampula. The study is based on professional experiences and literary works readings that theoretically discuss the phenomenon of school inclusion and present possible teacher-student, student-student interaction strategies among other actors in the process. The article does not provide solutions, but some suggestions in the form of models of procedures of the participants in the process of inclusion of students with special educational needs in regular classes.
\end{abstract}

Keywords: Model; Interaction; School inclusion; Children

\footnotetext{
*Doutorando de Piscologia Clínica da PUCRS-Brasil

${ }^{1}$ Nampula é uma província situada na região norte de Moçambique. A sua capital é a cidade de Nampula, localizada a cerca de $2150 \mathrm{~km}$ a norte da cidade de Maputo, a capital do país.
} 


\section{INTRODUÇÃO}

O artigo visa discutir a promoção do processo interativo de crianças portadoras de Necessidades Educativas Especiais em ambiente inclusitivo. O autor ficou familiarizado com as $\mathrm{NEE}^{1}$ desde a adolescência, do questionamento contínuo sobre a adaptação escolar das crianças portadoras de deficiências e o seu nível de interação com outros intervenientes. A motivação foi impulsionada quando o autor escolheu esta abordagem como tema para a culminação do curso na Graduação e, ser docente da disciplina de Necessidades Educativas Especiais em muitos cursos da Universidade Pedagógica de Moçambique, Delegação de Nampula, durante alguns anos. O estudo é fruto de experiências profissionais, apoiadas pelo levantamento bibliográfico. Associado a essas situações, o autor traz, neste artigo, uma abordagem sugestiva face aos modelos de interação da inclusão escolar em escolas regulares.

Historicamente, em Moçambique as crianças portadoras de deficiências não tinham oportunidades à educação formal. Após quinhentos anos de colonização portuguesa o país passou num longo período de reestruturação infraestrutural e dos profissionais. As crianças portadoras de deficiências eram vistas como incapazes para enfrentar o processo de ensino e aprendizagem. Posteriormente, no fim da década de 1990, o cenário começa a mudar com a Lei n ${ }^{\circ} 4 / 83$ do Sistema Nacional de Ensino (SNE), parágrafos 1 e 2 do art. 18 , que dá direito e oportunidade à educação a essa camada. Neste período, emergem as escolas privadas como promotores da educação especial. Por volta de 1998, Moçambique adaptou a política de educação inclusiva, implementando, assim, o Projeto-Piloto em cinco províncias, como resposta às orientações da Conferência Mundial sobre Necessidades Educativas Especiais de Salamanca em 1994. Em cada escola, havia uma sala reservada para crianças com deficiências auditivas, orientadas pelos professores com capacitação em Língua de Sinais. No entanto, as modalidades interação usadas nestas escolas careciam do componente inclusivo. As crianças portadoras de NEE estudavam, brincavam e interagiam entre elas, sendo que o ensino era mais especial do que inclusivo. Com o passar de tempo, a modalidade de inclusão escolar foi expandindo-se, abrangendo assim, outras escolas e cidades, mas com a mesma filosofia de interação. Esta situação contradizia ao objetivo do Ministério sobre a educação inclusiva, que considerava:

Será integrado nas escolas e salas de aula existentes o maior número possível de crianças com necessidades especiais, ao invés de segregá-las em escolas separadas ou excluí-las, por completo, da escola. O sucesso da inclusão vai exigir formação inicial e em exercício dos professores, de modo a prepará-los para as exigências de ensinar um grupo ainda mais diverso de alunos. Vai também exigir esforços de preparação dos pais e das comunidades para as mudanças que possam acompanhar a inclusão, nas suas escolas, bem como o desenvolvimento de estratégias de ensino e materiais apropriados para o uso em salas de aula inclusivas (MEC, 1998, p.37²).

Ao abrigo do Diploma Ministerial No 191/2011, de 25 de Julho, foram criados três Centros de Recursos de Educação Inclusiva (CREI) nas três regiões provinciais do país, sendo um na província de Gaza - Região Sul, outro na província de Tete - Região Central, e o terceiro na província de Nampula - Região Norte, para lecionarem os níveis Primário, Secundário e Profissional inclusivo. No Centro de Recurso da Educação Inclusiva Josina Machel, em Anchilo Nampula, região Norte, o processo inclusivo é notório, e os professores recebem formações e capacitações de curta duração regularmente. $\mathrm{O}$ aporte material neste centro é adequado, com salas especiais conforme as necessidades dos alunos. Além dos alunos internos, portadores de NEE, as salas são partilhadas com outros alunos externos considerados. Cada professor trabalha com crianças com uma necessidade e os que ajudam o professor a mediar, considerando um recurso. Além da atenção na sala de aula, os alunos são assistidos por um Terapeuta de Fala/de linguagem, Terapeutas Ocupacionais, Psicopedagogos, Assistente Social, e Serviços de Diagnóstico e Orientação, apesar destes não terem a formação específica na área.

Contrariamente, em outras escolas "regulares" com uma percentagem menor de crianças com necessidades educativas especiais, a modalidade de interação é desejável, além dos professores carecerem de formação e capacitação na matéria nas necessidades 
educativas especiais, as condições infraestruturais e materiais didáticos são quase inexistentes.

Neste estudo, discutimos a questão relacionada com s concepção teórica e prática curricular na inclusão, a formação de professores para a inclusão, a restruturação dos espaços para a inclusão, meios didáticos, currículo adaptado às individualidades do aluno, programação educacional inclusão, modelo interativo de inclusão escolar e considerações finais.

\section{TEORIA E PRÁTICA CURRICULAR NA INCLUSÃO}

O meio escolar é um espaço muito importante para qualquer criança, mas é ainda mais importante para a criança com deficiência porque é na escola onde ele encontra a sua inclusão desde as atividades educativas às lúdicas. É na escola que ela aprende a confiar em si, percebendo que é capaz de realizar a maioria das atividades que sozinha não pode executar, e vencer o seu ego e a sua autoestima.

A inclusão e interação escolar constituem processos que envolvem a adaptação do sistema escolar às necessidades dos alunos, permitindo que todos tenham a mesma oportunidade de saborear ao mesmo nível a abordagem e todo conhecimento em análise em classe e fora dela. É um tipo de aprendizagem implementada em escolas com diversidades em termos de natureza psicomotora e socioafetiva dos alunos, propondo um único sistema educacional para todos, com ou sem deficiência.

Reis, Silva \& Campos (2017, p.769) nos lembram que, com tal diversidade de alunos incluídos nas turmas regulares, nós, educadores, precisamos ter uma visão crítica do que está sendo exigido de cada aluno. Contudo, superar a lógica de adaptações pressupõe uma proposta curricular construída na perspectiva de viabilizar a articulação dos conhecimentos do ensino especial e do ensino comum; ambos devem promover a ampliação dos conhecimentos, das experiências de vida e a valorização dos recursos de aprendizagem. Assim, o aluno que possui limitações pode se desenvolver com auxílio de outros recursos que permitam a adaptação do currículo.

$\mathrm{Na}$ atualidade, o novo conjunto educativo, em Moçambique, centra-se na promoção inclusiva de alunos com NEE em diferentes escolas públicas. Em contrapartida, as escolas merecem uma restauração, desde a situação infraestrutural até a formação do corpo docente. As escolas devem formar outra imagem, começando com a adaptação dos espaços, materiais de apoio em salas de aula, preparação dos professores e sensibilização dos alunos; e a comunidade em geral. Em Moçambique, em Nampula em especial, a comunidade ainda continua com preconceitos e segregação para com as crianças portadoras de deficiências. Às vezes, a discriminação parte de casa, na família, e da comunidade.

\section{FORMAÇÃO DE PROFESSORES PARA INCLUSÃO}

Segundo Nhapuala \& Almeida (2016), as escolas devem receber todas as crianças, independentemente das suas condições físicas, intelectuais, sociais, emocionais, linguísticas ou outras. Isto inclui crianças com deficiências e sobredotadas, crianças de rua e crianças trabalhadoras, crianças de populações remotas ou nômades, crianças de minorias linguísticas, étnicas ou culturais, e crianças de outras áreas ou grupos desfavorecidos ou marginalizados. Esta é a razão pela qual a formação e a capacitação dos professores constitui uma estratégia para uma inclusão escolar adequada.
A inclusão é a aceitação da diversidade, na vida em sociedade, e também é a garantia do acesso das oportunidades para todos. Portanto, não é somente com leis e textos teóricos que iremos assegurar os direitos de todos, pois esses, por si mesmos, não garantem a efetivação das ações no cotidiano escolar (TEZANI, 2009, p.5).

É neste âmbito que este artigo traz uma abordagem crítica sobre as modalidades de interação na inclusão escolar em Moçambique, especialmente em Nhapuala. Portanto, as leis e todos os documentos normativos inerentes à inclusão em escolas regulares constituem uma conquista e um ganho social. No entanto, apesar da iniciativa educativa implementada em escolas regulares, falta a reestruturação do aspeto físico e organizacional e a capacitação de docentes para facilitares a adaptação adequada à nova filosofia. Assim, Silva, Ribeiro \& Carvalho (2013, p. 63) consideram que:

A Escola necessita de professores que saibam lidar com as NEE, daí a importância do corpo docente 
adquirir formação contínua na área da Educação Especial, que lhes permita obter conhecimentos para trabalharem em equipe e poderem planificar, intervir (utilizar materiais diversificados para apoio à prática pedagógica, incluindo o uso das novas tecnologias) e colaborar com o professor de educação especial, pais e restantes intervenientes. Os professores de educação especial estão mais vocacionados para a implementação de uma escola inclusiva e mais sensibilizados e habilitados profissionalmente para o trabalho com alunos caracterizados com NEE.

Esta ideia é comungada por Vasconcelos (2012, p.31), ao afirmar que "todos os professores necessitam de algum conhecimento sobre deficiências e dificuldades de aprendizagem, algumas competências para o ensino destes alunos, e a capacidade para contribuir para a avaliação de alunos com necessidades mais evidentes".

Nhapuala \& Almeida (2016) fundamentam, dizendo que o crescimento exponencial de alunos com NEE escolarizados em escolas regulares em Moçambique vem, precisamente, colocar desafios enormes às escolas regulares e aos professores, no sentido de responderem adequadamente às necessidades decorrentes desta prática, sobretudo num contexto em que a formação dos professores se mostrou claramente em descompasso com as necessidades cotidianas com as quais estes se deparavam nas salas de aulas. Contudo, o perfil de professor formado para atender o Ensino Básico, onde a inclusão escolar está sendo implementada, não capacita o professor para lidar com o processo. Portanto, os profissionais para este nível, atualmente, têm um ano na formação depois do nível básico geral. Ainda, o currículo é tão pobre que não contempla muitas abordagens e variedades de NEE.

Os autores continuam fundamentando, afirmando que o êxito da educação inclusiva depende da capacidade de resposta dos professores à diversidade na sala de aula. Portanto, a implementação do projeto da inclusão escolar devia vir acompanhada da formação do corpo docente. Os professores do ensino regular, em muitas circunstâncias, não se consideram devidamente preparados para gerir, de forma adequada, as dificuldades inerentes à diversidade dos alunos. Assim, num contexto escolar inclusivo, os docentes têm de adquirir e/ou aperfeiçoar as suas competências profissionais, sendo necessário que a escola e as entidades governamentais invistam na formação dos professores a este nível, principalmente contemplando os docentes do ensino regular, cuja área de formação profissional não é específica, nem direcionada para os alunos com NEE (SILVA, RIBEIRO, CARVALHO, 2013, p. 63).

\section{REESTRUTURAÇÃO DOS ESPAÇOS PARA A INCLUSÃO}

As escolas inclusivas não devem ter a mesma cara de outras escolas, consideradas normais. Nestas primeiras, o ambiente e as salas de aula devem responder à inclusão, ou seja, as escolas devem se adaptar às diversidades dos alunos, para garantir o acesso efetivo de todas as crianças.

Reis, Silva \& Campos (2017, p.766), referindose à restruturação dos espaços para a inclusão escolar, argumentam que:

Nas escolas de ensino regular, o $\mathrm{AEE}^{1}$ deve acontecer em salas de recursos multifuncionais, que deve ser um espaço organizado com materiais didáticos, pedagógicos, equipamentos e profissionais com formação para o atendimento às necessidades educacionais especiais, projetadas para oferecer suporte necessário a estes alunos, favorecendo seu acesso ao conhecimento. Neste sentido, consideramos o AEE oferecido na Sala de Recursos Multifuncionais um importante elemento no processo de aprendizagem do aluno com deficiência na sala de ensino regular.

Neste mesmo assunto, Ribeiro (2011, p. 80) nos recorda sobre a questão da acessibilidade, cuja concepção transcende as barreiras arquitetônicas e contempla várias outras dimensões, que vão desde as físico/arquitetônicas até as atitudinais. Para ele, esta última dimensão tem uma importância ímpar, uma vez que envolve componentes básicos (cognitivo, afetivo e comportamental), que trazem implicações significativas para a prática pedagógica e, consequentemente, para a inclusão na escola. A relevância dessa discussão está na necessidade de conhecermos as fragilidades e/ ou potencialidades referentes à acessibilidade nos ambientes escolares, pois essa é condição imprescindível para a construção de uma educação inclusiva, que pressupõe novas exigências à gestão da escola, da aula e do professor, para vencerem os desafios emergentes. Entretanto, salientamos que, em termos de acessibilidade, o cenário encontrado nos espaços escolares é

\footnotetext{
${ }^{1}$ Atendimento Educacional Especializado
} 
bastante preocupante, visto que ainda há um grande distanciamento entre a legislação e a realidade.

Assim, fazendo uma analogia entre as exigências aqui levantadas pelos autores e a realidade da inclusão em Moçambique, e em Nampula em particularidade, há muita coisa por se fazer, pois as escolas não estão preparadas para a inclusão verdadeiramente dita. Algumas escolas não possuem acesso adequado, como é o caso de rampas, corrimões, e muito menos salas e carteiras que se adequam às necessidades múltiplas.

\section{MEIOS DIDÁTICOS}

Os meios didáticos são materiais que o professor recorre para se apoiar no processo de ensino e aprendizagem facilitando a assimilação dos conteúdos tratados. Com eles, o aluno faz a ligação entre o abstrato e o real. E as escolas regulares não têm esses meios, o que pode dificultar em situações em que a escola inscreve aluno com NEE. É nestes termos que Ribeiro (2011, p. 90) desafia, dizendo que "é oportuno ainda mencionar que as escolas regulares, geralmente, não dispõem de recursos para atender às especificidades dos alunos com deficiência, tais como: livros em Braille, soroban, lupas, regletes, mapas táteis, gravadores e outros materiais didáticos necessários».

\section{CURRÍCULO ADAPTADO ÀS INDIVIDUALIDADES DO ALUNO}

A mudança de mentalidade dos gestores escolares (professores e toda comunidade escolar educativa) é o primeiro passo no processo de adaptação curricular para garantir o acesso aos conteúdos a todos alunos. Partindo do currículo único, o professor deve ser mais flexível possível em fazer ajustes para agregar e/ou excluir alguns pormenores, de modo a servir para todos os alunos.

As adaptações ao currículo devem contribuir para modificações nos aspetos físicos e administrativos, nos materiais, nos sistemas de comunicação, ou na previsão dos recursos especiais, para possibilitar que os alunos com deficiências possam desenvolver o currículo ordinário ou adaptado. Em sala de aula por exemplo, o professor deve fazer mudanças na linguagem, nas estratégias de operacionalização dos objetivos, conteúdos, critérios de avaliação, metodologias e materiais, para atender às necessidades individuais dos seus alunos. O professor, portanto, deve evidenciar a individualização do ensino.

Leite (2008, p.16) considera dois tipos de adaptações curriculares na inclusão escolar: adaptações curriculares de grande porte e adaptações curriculares de pequeno porte. A primeira forma refere-se a modificações que necessitam de aprovação técnico-político-administrativa para serem colocadas em prática. Assim, compreendem ações que são de responsabilidade de instâncias político-administrativas superiores, já que exigem modificações que envolvem ações de natureza política, administrativa, financeira, burocrática, entre outras. As adaptações de pequena escala são aquelas que envolvem modificações a serem realizadas no currículo e, portanto, são de responsabilidade do professor. Tais adaptações têm o objetivo de garantir que o aluno com deficiência possa acompanhar o processo de ensino e aprendizagem na sala comum da escola regular, com outros alunos da mesma idade que ele. A implementação de tais estratégias deve ser partilhada com outros profissionais da escola. Como se poder ver, a escola deve tomar consciência clara de que poderá cumprir o programa a seu modo, como consequência das característica e necessidades do seu meio socioeconômico e cultural, dos seus recursos existentes, dos interesses, expectativas, diferenças e motivações dos seus alunos.

\section{PROGRAMAÇÃO EDUCACIONAL INCLUSÃO}

Segundo Correia (2008, p.90) enfatiza que,

A fase de programação deve poder contar com um conjunto de serviços, muitos deles especializados devendo torna-se, sempre plural e interdisciplinar apoiando-se nas necessidades do aluno através de identificação das áreas que venham a beneficiar-se com uso de estratégias e actividades especificas ou seja, a programação deve basear-se não só na informação acerca das áreas fortes e necessidades do aluno, mas também na informação que dita o desfasamento entre as capacidades do aluno e as expectativas do contexto educacional em que está inserido.

O conjunto de serviços que autor se refere, trata-se de cada uma das intervenções prestadas por cada um dos domínios que se inserem na esfera de 
educação especial (educacional, psicológico, terapêutico, social e clínico).

\section{SERVIÇOS EDUCACIONAIS}

Aqui, a essência dos serviços educacionais consiste em assegurar uma programação educativa apropriada que tenha em conta as capacidades e necessidades da criança com necessidades educativas especiais que vise a facilitação das suas aprendizagens. Assim, a programação educacional individualizado, os conteúdos devem considerar:

- A descrição de áreas fortes, necessidades e estilos de aprendizagem do aluno, fazendo uso da informação providenciada por todos participantes (elementos de equipa multidisciplinar), incluindo os pais e próprio aluno;

- Estabelecer um conjunto de metas finais para o aluno, ou seja, articular comportamento e aptidões que se esperam do mesmo quando este deixar de ter apoios especializados ou finalizar o seu percurso escolar. Permitir que se estabeleça um conjunto de objetivos de longo prazo e explorar os serviços transacionais de que o aluno pode vir a necessitar.

- Estabelecer objetivos globais na programação educacional individualizada do aluno, baseados no conhecimento do seu nível de realização atual e do que se pretende que ele venha atingir.

- Estabelecer objetivos específicos que permitam atingir os objetivos globais, considerando assim critérios, procedimentos de avaliação.

\section{SERVIÇOS PSICOLÓGICOS}

Os serviços psicológicos são prestados por psicológicos (educacionais, clínicos) que proporcionam às crianças com NEE e às suas famílias, quando necessário. Que segundo os dizeres de Correia (2008, p.79), "geralmente, esses serviços iniciam-se durante a avaliação da criança e têm como finalidade determinar o seu funcionamento intelectual, comportamento, as dificuldades de aprendizagem especificas e as perturbações emocionais". Por tanto, esses serviços podem ainda ajudar os pais e outros membros da família da criança com NEE a perceberem o seu problema e a compreenderem o impacto que ele possa vir a ter nas suas vidas e na da própria criança.

\section{SERVIÇOS TERAPÊUTICOS}

Os serviços terapêuticos congregam as intervenções destinadas a melhorar o comportamento da criança em determinadas áreas do seu desenvolvimento. Segundo Correia (2008, p.80), “as formas mais comuns de tratamento dizem respeito à fisioterapia, à terapia ocupacional, à terapia da fala/linguagem e à terapia respiratória".

No caso das crianças com problemas de audição é usada a forma de terapia da linguagem, que, a intervenção pode recorrer o treino auditivo ou desenvolvimento de um sistema de comunicação que faça uso dos sons, gestos ou sinais manuais.

\section{SERVIÇOS SOCIAIS}

Nos serviços sociais, para além de serem essenciais na recolha de informação de modo a lhe permitir a elaboração da história compreensiva da criança, destina-se também a apoiar as famílias das crianças como NEE a lidar com as exigências e problemas com que têm se confrontar para atender às suas necessidades. Para garantir o acesso e oportunidade educativa, algumas entidades como as igrejas e outras organizações particulares, tem se envolvidos no apoio escolar de crianças com NEE, construindo escolas, centros de assistências e diversão.

\section{SERVIÇOS CLÍNICOS}

Trata-se de intervenção médica, os serviços devem ser prestados por um médico. Nas escolas atuais, para além da possibilidade de se poder recorrer a uma variedade de serviços (psicológicos, terapêuticos, sociais e clínicos), é importante que não se considere que o aluno tem um caminho definido a percorrer, traçado, essencialmente, por um conjunto de exigências curriculares predeterminadas. Devem ser as características e necessidades dos alunos a determinar o currículo a considerar, flexibilizando-se o trabalho em grupo e apresentando-se os assuntos de uma forma mais concreta e significativa possível para estimular a participação. 


\section{MODELO INTERATIVO DE INCLUSÃO ESCOLAR}

A inclusão é um componente de aceitação e integração de crianças com necessidades educativas especiais em classes regulares, com acompanhamento especializado de professor/pedagogo ou psicólogo com conhecimento na matéria. Esta ação implica uma preparação de todos os envolvidos, desde os pais e encarregados da educação, a escola (professores, alunos, currículo, métodos e meios didáticos), psicólogo e/ou profissionais da saúde, e a comunidade.

Quando se fala na figura dos pais e encarregados da educação, estamos nos referindo à primeira aceitação que a criança recebe quando nasce, ou nos primeiros momentos da identificação da patologia. Sabemos que alguns pais se revoltam quando o bebê, esperado com tanta expectativa, nasce com alguma deficiência.

Para Reis (2012, p.15), a família assume as funções de socialização primária, que consiste em transmitir características humanas básicas, tais como o afeto, a linguagem ou as interações sociais, assim como as particularidades próprias do grupo cultural ou familiar, tais como as crenças, valores e critérios morais.

Portanto, é na família onde devem se criar os primeiros laços de aceitação e inclusão de criança portadora de deficiência. Aliás, temos assistido, em algumas famílias, crianças com deficiências sendo postas de lado em comparação com as outras crianças da família consideradas normais. Isso não deveria acontecer. Todas as crianças são iguais e têm os mesmo direitos, independentemente da deficiência da qual ela é portadora. $\mathrm{O}$ comportamento de aceitação e inclusão deve se manifestar a todos os elementos que agregam a família, desde pais, irmãos, tios, entre outros.

A outra figura que integramos no modelo de inclusão é a própria escola. Estamos nos referindo aos professores, aos alunos e aos outros funcionários que partilham o espaço escolar com as crianças. Portanto, não basta que a criança tenha boa aceitação e socialização em casa, e na escola se deparar com situação contrária. Há professores que recusam classes com crianças com deficiências. Há alunos que negam aproximar-se do colega com alguma patologia. E existem funcionários na escola que se limitam a assistir enquanto alguma criança carece de apoio.

Outrossim, a direção da escola deve encontrar formas de restruturação do edifício, rampa de acesso, mobiliários, adaptação curricular, e outros meios para garantir o acesso e a inclusão do aluno com NEE, como está escrito na Declaração de Salamanca:

Escolas inclusivas devem reconhecer e responder às necessidades diversas de seus alunos, acomodando ambos os estilos e ritmos de aprendizagem e assegurando uma educação de qualidade a todos através de um currículo apropriado, arranjos organizacionais, estratégias de ensino, uso de recurso e parceria com as comunidades. Na verdade, deveria existir uma continuidade de serviços e apoio proporcional ao contínuo de necessidades especiais encontradas dentro da escola (REIS, 2012 p.29).

Outro profissional indispensável no estudo comportamental e nos níveis de assimilação dos conhecimentos é o psicólogo e/ou profissional de saúde. Estes trabalham com os transtornos e algumas perturbações que os pais, os professores e a comunidade em geral têm dificuldade de discriminar. Assim a escola, em coordenação com as direções distritais, provinciais e ministeriais, deve criar condições de integração do psicólogo com o serviço da aprendizagem das crianças.

No entanto, apesar de Moçambique formar Psicólogos Escolares, Psicólogos Educacionais e outros profissionais afins, não explora essas potencialidades. Nas escolas, os professores trabalham sem apoio algum para análise comportamental. Portanto, a inclusão escolar de crianças com NEE deve ser apoiada com profissionais que conhecem aspectos comportamentais.

$\mathrm{O}$ quarto elemento, dentro desse modelo de inclusão escolar das crianças com NEE, é a própria sociedade. No componente sociedade, neste modelo, inclui todos os intervenientes na interação social, desde a própria família, as confissões religiosas, os vizinhos, os pares, e todos aqueles que completam a nossa vida. Esses devem colaborar na inclusão da criança a partir da comunidade e sua aceitação. 
Figura: Modelo Interativo de inclusão escolar

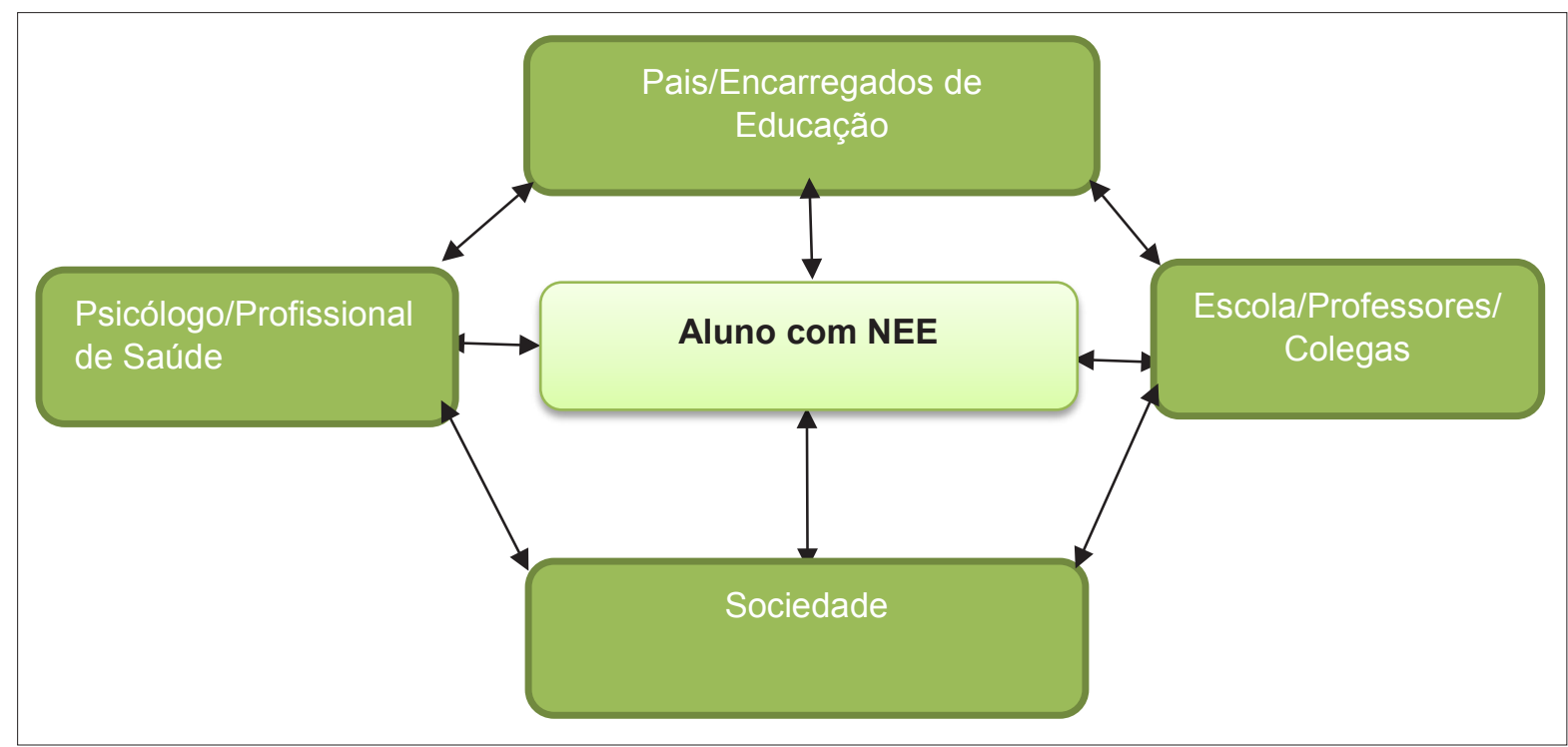

Fonte: Adaptação do autor

A interrelação e um trabalho cooperativo de todos os intervenientes constituem o alicerce para a inclusão escolar de crianças com Necessidades Educativas Especiais. No entanto, nenhum elemento do modelo é independente e suficientemente importante para garantir a socialização e inclusão das crianças, mas a presença de um complementa o sentido do outro, e todos, em conjunto, garantem o sucesso na educação inclusiva e integração social das crianças portadoras de deficiências.

\section{CONSIDERAÇÕES FINAIS}

A propósito do debate sobre a organização da escola para atender a diversidade e inclusão de todos os alunos, sobretudo, de crianças com deficiência, recobre de especial importância a discussão sobre o currículo escolar adotado e/ou formulados pelas escolas.

Este artigo é parte das estratégias de implementação de políticas de inclusão escolar que Moçambique vem promovendo para garantir o direito à educação para todos. O mesmo é fruto de uma análise crítica sobre as modalidades em que a inclusão é feita sem obediência aos pressupostos básicos para atender crianças portadoras de necessidades educativas especiais. Portanto, as escolas que integram no seu sistema este programa carecem de uma adaptação dos edifícios e ambiente escolar, de materiais de apoio aos alunos e professores, sendo que estes últimos não têm uma formação psicopedagógica aceitável. A proposta das políticas públicas educacionais para a construção de uma escola inclusiva e aberta a diversidade, observa-se que os órgãos governamentais ligados ao sector educacional, dão amplo apoio a construção de um currículo que atenda as necessidades educacionais especiais

A nossa reflexão sugere um modelo de inclusão como estratégia de conciliar a teoria com a prática curricular envolvendo todos intervenientes no processo escolar, desde a família, a escola, a comunidade e outros meios envolventes. No entanto, este não constitui um trabalho acabado, mas abre uma possibilidade de continuação da discussão sobre o tema para um propósito comum, "Educação para Todos", sem discriminação das particularidades individuais.

\section{REFERÊNCIAS}

CORREIA, L. M. Inclusão e Necessidades Educativas Especiais: um guia para educadores e professore. Porto editora. $2^{\text {a }}$ Ediçao, Lisboa, 2008.

NHAPUALA, G.; ALMEIDA, L. S. Formação de Professores e Inclusão em Moçambique. Universidade Minho. Journal of Research in Special Educational Needs. vol 16, n. s1, 2016, p. 520-523. Disponível em: https://onlinelibrary. wiley.com/doi/epdf/10.1111/1471-3802.12314, Acesso em: 16 de.abril.de 2018

MEC. Plano Estratégico de Educação 1999-2003: Combater a exclusão, renovar a escola. Maputo, 1998, p.1- 
43. Disponível em: http://www.mined.gov.mz/POEMA/ Biblioteca/PO-S1-PEE-99-2003.pdf, Acesso em: 16.04.2018

LEITE, L.P. Práticas educativas: adaptações curriculares. BAURU, 2008. Disponível em: http://www2.fc.unesp. br/educacaoespecial/material/Livro10.pdf, Acesso em: 16.04.2018

REIS, V.A.S. O envolvimento da família na educação de crianças com necessidades educativas especiais. Lisboa, 2012. Disponível em: https://comum.rcaap.pt/ bitstream/10400.26/2597/1/V\%C3\%A2niaReis.pdf, Acesso em: 16 de abril 2018

REIS, M.B.F.; SILVA, B.T.; CAMPOS, D.R. A inclusão na rede regular de ensino fundamental: espaços $\mathrm{e}$ desafios para aprendizagem. Inhumas: UEG, 2017, p. 761772. Disponível em: http://www.anais.ueg.br/index.php/ semintegracao/article/viewFile/8997/6992. Acesso em: 16 de abril de 2018

RIBEIRO, S. L. Acessibilidade para a inclusão na escola: princípios e práticas. Feira de Santana, n. 44,, jan./jun. 2011. p. 79-98. Disponível em: http://www2.uefs.br:8081/ sitientibus/pdf/44/C_evaz_Sitientibus_alvaro_artigos4.pdf , Acesso em: 16 de abril 2018

SILVA, M.D.O.; RIBEIRO, C.; CARVALHO, A. Atitudes e Práticas dos Professores Face à Inclusão de Alunos com Necessidades Educativas Especiais. Portugal, v. 47I, 2013, p. 53-73. Disponível em: http://impactum-journals. uc.pt/rppedagogia/article/download/1796/1145, Acesso em: 16 de abril 2018

TEZANI, T. C. R. A relação entre gestão escolar e educação inclusiva: o que dizem os documentos oficiais? São Paulo, 2009. Disponível em: https://seer.fclar.unesp.br/rpge/article/ download/9249/6131, Acesso em: 16 de abril de 2018

VASCONSELOS, C. R. M. Formação de Professores e Educação Inclusiva: uma perspetiva de docentes do 1. Ciclo do Ensino Básico na ilha de S. Miguel. Porto: Universidade Fernando Pessoa, 2012. Disponível em: https://bdigital.ufp.pt/bitstream/10284/3664/1/TESE\%20 FINAL\%20Cristina\%20Vasconcelos.pdf, Acesso em: 16 de abril de 2018 